\title{
Forgotten but Not Gone: Update on Measles Infection for Hospitalists
}

\author{
Ketino Kobaidze, MD, PhD, FHM, FACP ${ }^{1 *}$, Gregory Wallace, MD, MS, MPH² \\ ${ }^{1}$ Division of Hospital Medicine, Emory University School of Medicine, Atlanta, Georgia; ${ }^{2} E$ pidemiology Branch, Division of Viral Disease, National \\ Center for Immunization and Respiratory Disease, Centers for Disease Control and Prevention, Atlanta, Georgia.
}

\begin{abstract}
Measles (rubeola) continues to be endemic and epidemic in many regions of the world. Measles is primarily a disease of childhood, but it can also affect adult populations, and therefore it is important that both adult and pediatric hospitalist physicians be able to recognize it. Although the disease is rarely encountered in the United States, measles infection can spread rapidly across vulnerable populations. In addi-
\end{abstract}

tion, infected adults can develop complications that may require hospitalization for treatment. This review summarizes the typical clinical course and complications of measles infection, along with recommendations for diagnosis and management for both adult and pediatric hospitalists. Journal of Hospital Medicine 2017;12:472-476. (C) 2017 Society of Hospital Medicine
Measles is a highly contagious acute respiratory illness that includes a characteristic rash. After exposure, up to $90 \%$ of susceptible persons develop measles. ${ }^{1}$ Even though it is considered a childhood illness, measles can affect people of all age groups. Measles continues to be major health problem around the world, despite the availability of a safe and effective vaccine, and it remains one of the leading causes of childhood mortality, with nearly 115,000 deaths reported by the World Health Organization ${ }^{2}$ in 2014. In 2000, measles was declared eliminated from the United States, but outbreaks still occasionally occur. ${ }^{3-6}$

The disease is self-limited, but some patients develop complications that may require hospitalization for treatment. People at highest risk for complications are children younger than 5 years, adults older than 20 years, pregnant women, and immunocompromised individuals. ${ }^{7}$

\section{HISTORY AND EPIDEMIOLOGY}

During the licensure of live measles vaccine in 1963, an average of 549,000 measles cases and 495 measles deaths, as well as 48,000 hospitalizations and 4000 encephalitis cases, were reported annually in the United States. Almost all Americans were affected by measles by adolescence.

Implementation of the 1-dose vaccine program substantially reduced reported incidence in the United States by 1988, and led to a dramatic decline in measles-related hospitalizations and deaths. ${ }^{3-6}$ The 2-dose MMR (measles, mumps, rubella) vaccination was introduced in 1989, and measles was declared eliminated in the United States in 2000.-6

National-level one-dose MMR coverage among children 19-35 months has remained above $90 \%$ during the last two

\footnotetext{
*Address for correspondence and reprint requests: Ketino Kobaidze, MD, $\mathrm{PhD}$, FHM, FACP, Division of Hospital Medicine, Emory University School of Medicine, 550 Peachtree St, Atlanta, GA 30308; Telephone: 404-686-8263; Fax: 404-686-4837; E-mail: kkobaid@emory.edu
}

Received: March 1, 2016; Revised: November 4, 2016; Accepted: November 28, 2016

2017 Society of Hospital Medicine DOI 10.12788/jhm.2752 decades. ${ }^{8}$ NIS-Teen vaccination coverage data for 13 - to 17 -year-olds since 2008 has been near or above $90 \%,{ }^{9}$ and $94 \%$ of children enrolled in kindergarten had evidence of 2 MMR doses in the 2014-2015 school year. ${ }^{10}$

A large multistate measles outbreak was reported in the United States in 2014-2015.4,11 One hundred fifty-nine cases were reported in the United States between January 4 and April 5, 2015. The majority of patients either were unvaccinated $(45 \%)$ or had an unknown vaccination status $(38 \%)$. Age ranged from 6 weeks to 70 years, and 22 patients (14\%) were hospitalized. ${ }^{4}$

\section{CLINICAL PRESENTATION AND PATHOPHYSIOLOGY}

Measles is caused by an RNA-containing paramyxovirus that is spread by the respiratory route. Average incubation period from exposure to rash onset is 14 days (range, $7-21$ days). ${ }^{12,13}$ Peak infectivity occurs during the prodromal phase, before rash onset (Figure 1), but patients are infectious from 4 days before rash onset through 4 days after rash onset. ${ }^{7,12,13}$

The disease prodrome consists of a high fever $\left(39^{\circ} \mathrm{C}-40.5^{\circ} \mathrm{C}\right)$, coryza, cough, and conjunctivitis followed by Koplik spots (Figure 2A). Koplik spots are pathognomonic for measles but rarely discovered. They appear before the skin rash alongside second molars on the buccal surface of the cheeks. The spots usually disappear when the characteristic maculopapular, nonpruritic rash erupts initially at the hairline and behind the ears, and within four days progresses toward the trunk and limbs, including the palms and soles (Figures 2B, 2C).

The patient remains febrile while the rash spreads. ${ }^{12,13}$ Usually the fever resolves while the rash fades in the same order in which it appeared. Fever that persists for more than 5 days usually indicates complications. ${ }^{13}$

Cellular immunity plays an important role in host defense; the virus invades $\mathrm{T}$ lymphocytes and triggers suppressive cytokine (interleukin 4) production. Leukopenia, expansion of mainly measles-specific $\mathrm{T}$ and $\mathrm{B}$ lymphocytes, and replacement of lymphocyte memory cell population results in further depression of cellular immunity, and predisposes 


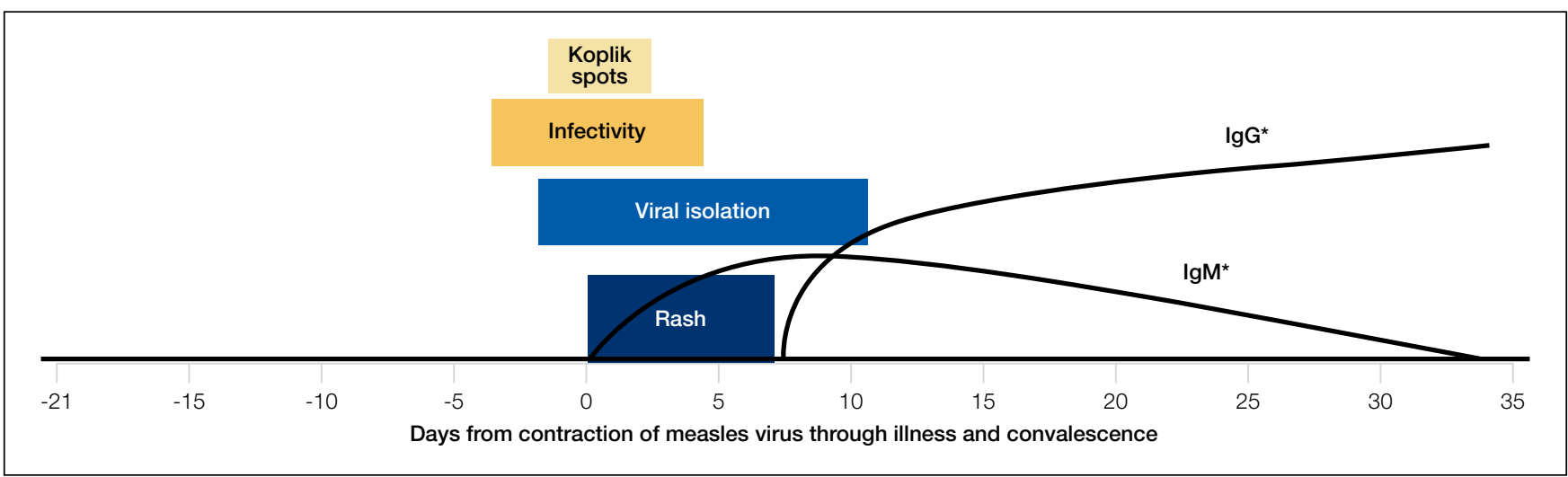

FIG. 1. Measles infection associated rash in relation to infectivity, viral detection, and serologic response. Immunocompromised patient can continue to shed virus for entire duration of disease. Viral isolation is optimal during 0 to 3 days of rash onset but can be detected through 2 days before and 10 days after rash onset. Average incubation period from exposure to rash is 14 days, but incubation period can vary from 7 to 21 days.

NOTE: *Applies to unvaccinated individuals. Dark blue box, rash duration; light blue box, viral isolation duration; gold box, infectivity duration; light gold box, Koplik spots duration; curve lgM, duration immunoglobulin M (lgM) is detected in serum; curve $\lg \mathrm{G}^{\star}$, duration immunoglobulin $\mathrm{G}(\mathrm{lg} \mathrm{G})$ is detected in serum.
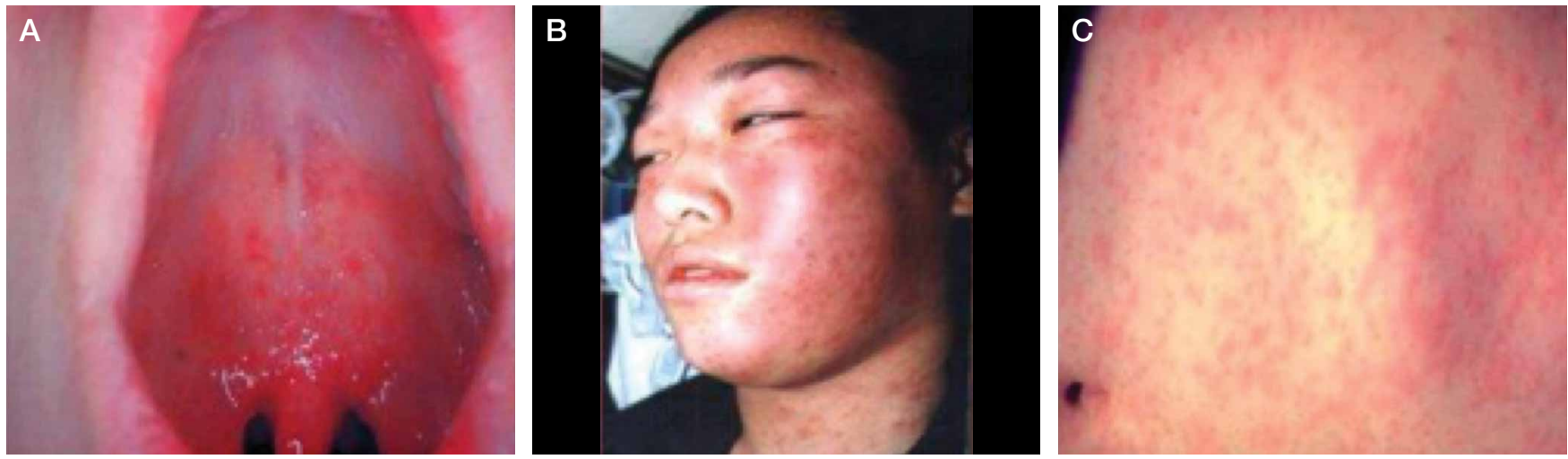

FIG. 2. (A) Pathognomonic buccal exanthem, Koplik spots. (B) Typical small, reddish, flat, macular and papular exanthemous rash on head and neck of patient with measles infection. (C) Rash spreads to arms, back, upper trunk, and legs. Courtesy of Centers for Disease Control and Prevention image library.

patients to secondary bacterial infections for up to 2 years after measles infection. ${ }^{14,15}$

Patients immunocompromised by congenital cellular immunity deficiency, cancer, human immunodeficiency virus (HIV) infection without effective antiretroviral therapy, or immunosuppression treatment are at higher risk for developing severe complications or dying from measles. As the rash may fail to develop in these patients, diagnosis can be challenging. ${ }^{16}$

Modified measles is milder and may occur in patients with preexisting partial immunity: those with an immunization history ( 2 -dose vaccine effectiveness is $\sim 97 \%$ ), and infants with minimal immunity from their mothers. ${ }^{1,7}$ Patients may have mild respiratory symptoms with rash but little or no fever. ${ }^{?}$

Atypical measles is now extremely rare. It was described only among people who were vaccinated with the killed vaccine in the United States between 1963 and 1968 and subsequently exposed to measles. The disease is characterized by high fever, edema of extremities, and a rash that develops on the palms and soles and spreads centerward. It is considered noncommunicable. ${ }^{17}$
Measles infection during pregnancy is associated with increased maternal and fetal morbidity. The virus can induce neonatal low birth weight, spontaneous abortion, intrauterine fetal death, and maternal death. Pregnant women with measles are more likely to be hospitalized. ${ }^{18,19}$

\section{DIFFERENTIAL DIAGNOSIS}

The presenting symptoms of primary measles infection are nonspecific, particularly if Koplik spots are not identified. The differential diagnosis for a patient who presents with high fever and rash include Kawasaki disease, dengue, parvovirus B19, serum sickness, syphilis, systemic lupus erythematous, toxic shock syndrome, enterovirus infection, human herpes virus 6 (roseola), viral hemorrhagic fever, drug eruption, infectious mononucleosis, Rocky Mountain spotted fever, rubella, scarlet fever, chikungunya, and Zika virus infection.

\section{COMPLICATIONS}

Measles complications can affect nearly every organ system (Table). Rates of complications from measles infection depend on age and underlying condition. Coexisting vitamin 
A deficiency increases complication rates. ${ }^{20}$

Bacterial infections in the setting of measles infection are more common in adults than in children, and are more severe among people who are malnourished or have an immunodeficiency disorder. The most common infectious complications, which involve the respiratory tract, include pneumonia, laryngotracheitis ("measles croup"), bronchitis, otitis media (most common complication among children in the United States), and sinusitis. ${ }^{7,13,21}$

Indications for hospitalizing children include respiratory distress, laryngeal obstruction, dehydration that requires intravenous fluids, diarrhea with more than 10 stools a day or bloody stool, severe anemia, altered mental status, convulsion, severe rash with developing hemorrhagic areas, extensive mouth ulcers, corneal clouding or ulcers, visual disturbance, and mastoiditis. ${ }^{22}$

Pneumonia is a common indication for hospitalizing adults. ${ }^{23,24}$ Measles-associated interstitial giant cell (Hecht) pneumonia is most often recognized among immunocompromised and malnourished patients. ${ }^{13}$ Primary pneumonia is caused by the measles virus, but bacterial superinfection can occur. The most common bacterial pathogens include Streptococcus, Pneumococcus, and Staphylococcus, ${ }^{13,24}$ and less commonly isolated organisms include gram-negative bacteria, such as Haemophilus influenzae, Pseudomonas aeruginosa, Neisseria meningitides, and Enterobacter cloacae. ${ }^{23}$

Uncommon complications of measles are myocarditis, glomerulonephritis, acute renal failure, and thrombocytopenic purpura. $^{25,26}$

Neurologic complications in measles are an important concern. Measles-associated central nervous system complications are considered a result of an immune-mediated reaction to myelin protein and not from direct viral insult. ${ }^{26-28}$ Immunocompromised patients are at risk for developing fatal encephalitis, and those who survive often experience cognitive decline or seizures.

Measles is associated with four different encephalitic diseases: primary measles encephalitis, acute post-measles encephalomyelitis, measles inclusion body encephalitis, and subacute sclerosing panencephalitis.

Primary measles encephalitis is characterized by fever, headache, stiff neck, and meningeal signs. Onset occurs between 1 and 15 days after rash onset, and the disease affects $1 / 1000$ patients. Seizure, altered mental status, and coma can also develop. Viral RNA detection in the cerebrospinal fluid (CSF) confirms the diagnosis. ${ }^{29}$

Acute post-measles encephalomyelitis is more common in adults than in children. ${ }^{12}$ It typically develops after the rash fades and the other symptoms subside. Patients suddenly experience a recurrence of fevers or seizures. Deafness, intellectual decline, epilepsy, postencephalitic hyperkinesia, hemiplegia, and/or paraplegia also can develop. ${ }^{27-29}$

Measles inclusion body encephalitis is described only in immunocompromised patients, and onset occurs within 1 year of infection. Seizures are an initial and common symptom, and some patients also experience hemiplegia, stupor, hy-
TABLE. Measles Infection Complications by Organ Systems

\begin{tabular}{|c|c|}
\hline Organ System & Complications \\
\hline Respiratory & $\begin{array}{l}\text { Laryngotracheitis (measles croup) } \\
\text { Measles pneumonitis } \\
\text { Pneumonia (bacterial) } \\
\text { Hecht (giant cell) pneumonia } \\
\text { Bronchitis } \\
\text { Respiratory distress } \\
\text { Acute respiratory distress syndrome } \\
\text { Pneumothorax } \\
\text { Pneumomediastinum }\end{array}$ \\
\hline Ears, nose, throat & $\begin{array}{l}\text { Otitis media } \\
\text { Pharyngitis } \\
\text { Sinusitis } \\
\text { Mastoiditis } \\
\text { Stomatitis }\end{array}$ \\
\hline Dermatologic & $\begin{array}{l}\text { Severe desquamation } \\
\text { Ulceration } \\
\text { Cellulitis }\end{array}$ \\
\hline Neurologic & $\begin{array}{l}\text { Headache } \\
\text { Nuchal rigidity } \\
\text { Febrile seizure } \\
\text { Delirium } \\
\text { Optic neuritis } \\
\text { Guillain-Barré syndrome } \\
\text { Acute viral encephalitis } \\
\text { Post-measles encephalomyelitis } \\
\text { Inclusion body encephalitis (in immunocompromised patients) } \\
\text { Subacute sclerosing panencephalitis } \\
\text { Transverse myelitis (rare) } \\
\text { Ataxia } \\
\text { Cognitive decline } \\
\text { Paralysis } \\
\text { Coma }\end{array}$ \\
\hline Gastrointestinal & $\begin{array}{l}\text { Hepatitis } \\
\text { Elevated liver enzymes without jaundice } \\
\text { Diarrhea } \\
\text { Mesenteric adenitis } \\
\text { Colitis } \\
\text { Ileitis } \\
\text { Appendicitis }\end{array}$ \\
\hline Renal & $\begin{array}{l}\text { Glomerulonephritis (rare) } \\
\text { Acute renal injury } \\
\text { Dehydration } \\
\text { Rhabdomyolysis }\end{array}$ \\
\hline Cardiac & $\begin{array}{l}\text { Myocarditis (rare) } \\
\text { Pericarditis }\end{array}$ \\
\hline Ophthalmologic & $\begin{array}{l}\text { Photophobia } \\
\text { Corneal clouding } \\
\text { Corneal ulcers } \\
\text { Blindness }\end{array}$ \\
\hline Hematologic & $\begin{array}{l}\text { Anemia } \\
\text { Thrombocytopenia with purpura } \\
\text { Leukopenia }\end{array}$ \\
\hline
\end{tabular}

pertonia, and dysarthria. ${ }^{29}$ Diagnostic findings include seroconversion during the disease course, improvement after withholding of the immunosuppressive regimen, and normal CSF. Brain biopsy confirms the diagnosis.

Subacute sclerosing panencephalitis (SSPE) is a slowly pro- 
gressing and untreatable degenerative neurologic disorder characterized by demyelination of multiple brain areas. SSPE develops 7 to 10 years after natural measles infection, and usually affects children or adolescents. Clinical presentation includes intellectual decline, frequent rhythmic myoclonic jerks, seizure, and dementia. As the disease progresses, coma, quadriplegia, vegetative state, and autonomic instability develop. Death usually occurs within 2 years of onset. ${ }^{30,31}$ In children, the risk for SSPE after measles infection is estimated to be 4 to 11 per 100,000 infections. After the 1989-1991 resurgence of measles in the United States, however, the risk for SSPE was estimated to be 22 per 100,000 infections. ${ }^{30-32}$ The pathogenesis of SSPE is not fully understood but is thought to result from persistent aberrant measles virus infection. ${ }^{32}$

The SSPE diagnosis is based on clinical presentation, presence of anti-measles antibodies in CSF, typical electroencephalography pattern (periodic paroxysmal bursts) with accompanying myoclonus, tissue analysis, and magnetic resonance imaging. ${ }^{30}$

\section{LABORATORY DIAGNOSIS}

Suspicion for measles should prompt immediate consultation with local or state public health officials. Laboratory testing can be carefully considered after consultation, and care is needed in interpreting serologic studies.

The mainstays of measles infection diagnosis are detection of viral RNA by reverse transcriptase-polymerase chain reaction, or isolation of the virus in the clinical specimen, and detection of measles-specific IgM (immunoglobulin $\mathrm{M}$ ) antibodies. A detailed protocol for collecting specimens for viral isolation appears on the Centers for Disease Control and Prevention website (http://www.cdc.gov/measles/labtools/rt-pcr.html).

IgM antibodies are detectable over the 15 weeks after rash onset, but the recommendation is to collect serum between 72 hours and 4 weeks after rash onset. ${ }^{33}$ Clinicians should be aware that false-positive IgM results may occur with rheumatologic diseases, parvovirus B19 infection, rubella, and infectious mononucleosis.

IgG (immunoglobulin $\mathrm{G}$ ) antibodies are usually detectable a week after rash onset. The laboratory can confirm measles by detecting more than a 4 -fold increase in IgG titers between the acute phase and the convalescent phase. After measles infection, most adults develop lifelong immunity with positive IgG serology. ${ }^{34}$

Additional tests, such as IgG avidity and plaque reduction neutralization assay, can be used to confirm suspected cases in previously vaccinated individuals. ${ }^{34}$

\section{MANAGEMENT}

\section{General Principles}

Uncomplicated measles treatment is supportive and includes oral fluids and antipyretics. ${ }^{7,22}$ Severe bacterial infections, encephalitis, or dehydration may require hospitalization, and in these cases infectious disease consultation is recommended. Patients with pneumonia, purulent otitis media, or tonsillitis should be treated with antibiotics. ${ }^{35}$ Observational data suggest antibiotics may reduce the occurrence of bacterial infection in children, but there are no usage guidelines. ${ }^{35}$ Vitamin A supplementation has been associated with a 50\% decrease in morbidity and mortality and with blindness prevention. ${ }^{22}$ This supplementation should be considered in severe measles cases (all hospitalized patients), especially for children, regardless of country of residence, and for adult patients who exhibit clinical signs of vitamin A deficiency. 22,24

\section{Antiviral Treatment}

No specific treatment is available. ${ }^{36}$ Ribavirin demonstrates in vitro activity against the virus, but the Food and Drug Administration has not approved the drug for treatment of measles. Ribavirin has been used for cases of severe measles, and for patients with SSPE along with intrathecal interferon alpha. This antiviral treatment is considered experimental. ${ }^{37}$

All patients hospitalized with measles infection should be cautioned about the potential downstream complications of the disease and should follow up with their primary care physician for surveillance after discharge. ${ }^{38}$

If measles symptoms develop, patients should self-quarantine and contact their primary care physician or public health department as soon as possible. Regardless of immune status, family members and other exposed persons should be educated about the measles symptoms that may occur during the 21 days after exposure. ${ }^{38}$

Both suspected and confirmed cases of measles should be reported immediately to local public health authorities.

\section{Infection Control and Prophylaxis}

Current guidelines recommend 2 doses of measles-containing vaccine to all adults at higher risk for contracting measles: international travelers, healthcare personnel, and high school and college students. Infants 6 or 11 months old should receive 1 MMR dose before international travel. ${ }^{1,38}$

Strict airborne isolation-use of N95 respirator or respirator with similar effectiveness in preventing airborne transmission-is mandatory from 3 to 5 days before rash onset to 4 days after rash onset (immunocompetent patients) or for the duration of the disease (immunocompromised patients). ${ }^{38}$

Healthcare workers should have documented presumptive evidence of immunity to measles. ${ }^{39}$ Healthcare providers without evidence of immunity should be excused from work from day 5 to day 21 of exposure, even if they have received postexposure vaccine or intramuscular immunoglobulin. They should be offered the first MMR dose within 72 hours of measles exposure to prevent or modify the disease. Susceptible family members or visitors should not be allowed in the patient's room. ${ }^{1}$

\section{Postexposure Prophylaxis}

Standard MMR vaccination within 72 hours after exposure may protect against disease in people without a contraindication to measles vaccine. The public health department usually identifies these individuals and provides postexposure prophylaxis recommendations. ${ }^{38,39}$ 
People with HIV, patients receiving immunosuppressive therapy, and pregnant women and infants who have been exposed to measles and who are at risk for developing morbid disease can be treated with immunoglobulin (IG). If administered within 6 days of exposure, IG can prevent or modify disease in people who are unvaccinated or severely immunocompromised (ie, not immune). The recommended dose of IG administered intramuscularly is $0.5 \mathrm{~mL} / \mathrm{kg}$ of body weight (maximum, $15 \mathrm{~mL}$ ), and the recommended dose of IG given intravenously is $400 \mathrm{mg} / \mathrm{kg}$. Anyone heavier than $30 \mathrm{~kg}$ would require intravenous IG to achieve adequate antibody levels.

Physicians should not vaccinate pregnant women, patients with severe immunosuppression from disease or therapy, patients with moderate or severe illness, and people with a history of severe allergic reaction to the vaccine. ${ }^{1,40}$ The measles vaccine should be deferred for 6 months after IG administration. ${ }^{36}$ More details are available in the recommendations made by the Advisory Committee on Immunization Practices.

\section{CONCLUSION}

Although rare in the United States, measles remains a common and potentially devastating infection among patients who have not been vaccinated. Diagnosis requires clinical suspicion, engagement of public health authorities, and judicious use of laboratory testing. Hospitalists may encounter infectious and neurologic complications of measles long after the initial infection and should be aware of these associations.

Disclosure: Nothing to report.

\section{References}

1. McLean HQ, Fiebelkorn AP, Temte JL, Wallace, GS; Centers for Disease Control and Prevention. Prevention of measles, rubella, congenital rubella syndrome, and mumps, 2013: summary recommendations of the Advisory Committee on Immunization Practices (ACIP). MMWR Recomm Rep. 2013;62(RR-04):1-34.

2. World Health Organization. Measles [fact sheet]. http://www.who.int/mediacentre/factsheets/fs286/en/. Accessed April 27, 2017.

3. Kutty P, Rota J, Bellini W, Redd SB, Barskey A, Wallace G. Chapter 7: measles. In: Manual for the Surveillance of Vaccine-Preventable Disease. 6th ed. https://www.cdc. gov/vaccines/pubs/surv-manual/chpt07-measles.html. Published 2013. Accessed April 27, 2017.

4. Clemmons NS, Gastanaduy PA, Fiebelkorn AP, Redd SB, Wallace GS; Center for Disease Control and Prevention (CDC). Measles-United States, January 4-April 2, 2015. MMWR Morb Mortal Wkly Rep. 2015;64(14):373-376.

5. Fiebelkorn AP, Redd SB, Gallagher K, et al. Measles in the United States during the postelimination era. J Infect Dis. 2010;202(10):1520-1528.

6. Fiebelkorn AP, Redd SB, Gastañaduy PA, et al. A comparison of postelimination measles epidemiology in the United States, 2009-2014 versus 2001-2008. J Pediatric Infect Dis Soc. 2017;6(1):40-48.

7. Gershon A. Measles (rubeola). In: Braunwald E, Fauci AS, Kasper DL, Hauser SL, Longo DL, Jameson JL, eds. Harrison's Principles of Internal Medicine. 15th ed. New York, NY: McGraw-Hill; 2001:1143-1145.

8. Hill HA, Elam-Evans LD, Yankey D, Singleton JA, Kolasa M. National, state, and selected local area vaccination coverage among children aged 19-35 monthsUnited States, 2014. MMWR Morb Mortal Wkly Rep. 2015;64(33):889-896.

9. Reagan-Steiner S, Yankey D, Jayarajah J, et al. National, state and selected local area vaccination coverage among children aged 13-17 years-United States, 2014. MMWR Morb Mortal Wkly Rep. 2015;64(29):784-792.

10. Seither R, Calhoun K, Knighton CL, et al. Vaccination coverage among children in kindergarten-United States, 2014-15 school year. MMWR Morb Mortal Wkly Rep. 2015;64(33):897-904.

11. Zipprich J, Winter K, Hacker J, Xia D, Watt J, Harriman K; Centers for Disease Control and Prevention (CDC). Measles outbreak-California, December
2014-February 2015. MMWR Morb Mortal Wkly Rep. 2015;64(6):153-154.

12. Perry RT, Halsey NA. The clinical significance of measles: a review. J Infect Dis. 2004;189(suppl 1):S4-S6.

13. Bernstein DI, Schiff GM. Measles. In: Gorbach SL, Bartlett JG, Blacklow NR, eds. Infectious Diseases. Philadelphia, PA: Saunders; 1998:1296.

14. Scheider-Schaulies S, Schneider-Schaulies J. Measles virus induced immunosuppression. Curr Top Microbiol Immunol. 2009;330:243-69

15. Mina MJ, Metcalf JE, de Swart RL, Osterhaus AD, Grenfell BT. Vaccines. Longterm measles-induced immunomodulation increases overall childhood infectious disease mortality. Science. 2015;348(6235):694-699.

16. Kaplan LJ, Daum RS, Smaron M, McCarthy CA. Severe measles may occur in immunocompromised patients. JAMA. 1992;267(9):1237-1241.

17. Melenotte C, Cassir N, Tessonnier L, Brouqui P. Atypical measles syndrome in adults: still around [published online September 23, 2015]. BMJ Case Rep. doi:10.1136/bcr-2015-211054.

18. Ogbuano IU, Zeko S, Chu SY, et al. Maternal, fetal and neonatal outcomes associated with measles during pregnancy: Namibia, 2009-2010. Clin Infect Dis. 2014;58(8):1086-1092

19. Rasmussen SA, Jameson DJ. What obstetric healthcare providers need to know about measles and pregnancy. Obstet Gynecol. 2015;126(1):163-170.

20. Davis AT. Exanthematous diseases. In: Shulman ST, Phair JP, Peterson LR, Warren JR, eds. The Biologic and Clinical Basis of Infectious Diseases. 5th ed. Philadelphia, PA: Saunders; 1997:467-469.

21. Fortenberry JD, Mariscalco MM, Louis PT, Stein F, Jones JK, Jefferson LS. Severe laryngotracheobronchitis complicating measles. Am J Dis Child. 1992;146(9):1040-1043.

22. World Health Organization, Department of Immunization, Vaccines and Biologicals. Treating Measles in Children. http://www.who.int/immunization/programmes systems/interventions/TreatingMeaslesENG300.pdf. Published 1997. Updated 2004. Accessed April 27, 2017.

23. Rafat C, Klouche K, Ricard JD, et al. Severe measles infection: the spectrum of disease in 36 critically ill adult patients. Medicine (Baltimore). 2013;92(5): 257-272.

24. Ortac Ersoy E, Tanriover MD, Ocal S, Ozisik L, Inkaya C, Topeli A. Severe measles pneumonia in adults with respiratory failure: role of ribavirin and high-dose vitamin A. Clin Respir J. 2016;10(5):673-675.

25. Chassort A, Coutherut J, Moreau-Klein A, et al. Renal dysfunction in adults during measles. Med Mal Infect. 2015;45(5):165-168.

26. Sunnetcioglu M, Baran A, Sunnetcioglu A, Mentes O, Karadas S, Aypak A. Clinical and laboratory features of adult measles cases detected in Van, Turkey. J Pak Med Assoc. 2015;65(3):273-276

27. Honarmand S, Glaser CA, Chow E, et al. Subacute sclerosing panencephalitis in the differential diagnosis of encephalitis. Neurology. 2004;63(8):1489-1493.

28. Liko J, Guzman-Cottrill JA, Cieslak PR. Notes from the field: subacute sclerosing panencephalitis death-Oregon, 2015. MMWR Morb Mortal Wkly Rep. 2016;65(1): $10-11$

29. Fisher DL, Defres S, Solomon T. Measles-induced encephalitis. QJM. 2015;108(3):177-182

30. Rodriguez D, Fishman D. Measles and subacute sclerosing panencephalitis. In: Samuels MA, Feske SK, eds. Office Practice of Neurology. Philadelphia, PA: Churchill Livingstone; 2003:419-420.

31. Gutierrez J, Issacson RS, Koppel BS. Subacute sclerosing panencephalitis: an update. Dev Med Child Neurol. 2010;52(10):901-907.

32. Bellini WJ, Rota JS, Lowe LE, et al. Subacute sclerosing panencephalitis: more cases of this fatal disease are prevented by measles immunization than was previously recognized. J Infect Dis. 2005;192(10);1686-1693.

33. Helfand RF, Heath JL, Anderson LJ, Maes EF, Guris D, Bellini WJ. Diagnosis of measles with an IgM capture EIA: the optimal timing of specimen collection after rash onset. J Infect Dis. 1997;175(1):195-199.

34. Hickman CJ, Hyde TB, Sowers SB, et al. Laboratory characterization of measles virus infection in previously vaccinated and unvaccinated individuals. J Infect Dis. 2011;204(suppl 1):S549-S558.

35. Kabra SK, Lodha R. Antibiotics for preventing complications in children with measles. Cochrane Database Syst Rev. 2013;(8):CD001477.

36. Sabella C. Measles: not just a childhood rash. Cleve Clin J Med. 2010;77(3): 207-213.

37. Hosoya M, Shigeta S, Mori S, et al. High-dose intravenous ribavirin therapy for subacute sclerosing panencephalitis. Antimicrob Agents Chemother. 2001;45(3):943-945.

38. Siegel JD, Rhinehart E, Jackson M, Chiarello L; Healthcare Infection Control Practices Advisory Committee. 2007 Guideline for Isolation Precautions: Preventing Transmission of Infectious Agents in Healthcare Settings. Centers for Disease Control and Prevention website. https://www.cdc.gov/hicpac/pdf/isolation/isolation2007. pdf. Accessed April 27, 2017.

39. Houck P, Scott-Johnson G, Krebs L. Measles immunity among community hospital employees. Infect Control Hosp Epidemiol. 1991;12(11):663-668.

40. Kumar D, Sabella C. Measles: back again. Cleve Clin J Med. 2016;83(5):340-344. 